EGU2020-10284

https://doi.org/10.5194/egusphere-egu2020-10284

EGU General Assembly 2020

(c) Author(s) 2020. This work is distributed under

the Creative Commons Attribution 4.0 License.

\title{
Anisotropy of magnetic susceptibility (AMS) of lava and volcanoclastic flows of the Stephano-Permian Cadi basin (central- eastern Pyrenees)
}

\author{
Ana Simon-Muzas ${ }^{1}$, Antonio M Casas-Sainz ${ }^{1}$, Ruth Soto ${ }^{2}$, Josep Gisbert ${ }^{1}$, Teresa Román-Berdiel ${ }^{1}$, \\ Belén Oliva-Urcia ${ }^{3}$, Emilio L Pueyo ${ }^{2}$, and Elisabet Beamud ${ }^{4}$ \\ 'Zaragoza, Geotransfer-IUCA, Ciencias de la Tierra, Spain (simonanamu14@gmail.com) \\ ${ }^{2}$ Instituto Geológico y Minero de España (IGME). Unidad de Zaragoza, 50006, Zaragoza, Spain \\ ${ }^{3}$ Universidad Autónoma de Madrid, Spain \\ ${ }^{4}$ Unitat de Paleomagnetisme (CCITUB-CSIC), ICT Jaume Almera, Barcelona, Spain
}

The aim of this work is to apply the anisotropy of magnetic susceptibility (AMS) to determine the primary and tectonic fabrics of lava flows and volcanoclastic materials in one of the Pyrenean Stephano-Permian basins.

The Pyrenean Range is a double vergence orogen located at the northern end of the Iberian Peninsula. During Carboniferous-Early Permian times the extensional or transtensional regime dominant during the progressive dismantling of the Variscan belt resulted in the development of $\mathrm{E}$ W elongated intra-mountainous basins. This process was coeval with an exceptional episode of magmatic activity, both intrusive and extrusive. The Cadí basin represents a good example of these structures were Stephano-Permian rocks are aligned along an E-W continuous outcrop and reach thickness of several hundreds of meters. The stratigraphy of the study area is characterized by fluviolacustrine sediments changing laterally to volcanoclastic and pyroclastic rocks with interbedded andesitic lava flows.

A total of 75 sites (733 standard specimens) were studied and analysed throughout the volcanoclastic, volcanic and intrusive materials of the Stephano-Permian outcrops in the Cadí basin. Samples were drilled in the field along 5 sections with N-S or NW-SE direction in the Grey and Transition Unit. Afterwards, standard specimens were measured in a Kappabridge KLY-3 (AGICO) at the Zaragoza University to characterise the magnetic fabric. The susceptibility bridge combined with a CS-3 furnace (AGICO) was used for the temperature-dependent magnetic susceptibility curves (from 20 to $700^{\circ} \mathrm{C}$ ) to recognize the magnetic mineralogy. In addition, textural and mineralogical recognition in thin-sections of the samples was carried out in order to recognize the relationship between magnetic and petrographic fabrics.

The results shows that the bulk magnetic susceptibility of the specimens ranges between 118 and $9060 \cdot 10^{-6} \mathrm{SI}$ but most of the values are bracketed between 160 to $450 \cdot 10^{-6} \mathrm{SI}$. Taking into account magnetic parameters $(\mathrm{Km}, \mathrm{Pj}$ and $\mathrm{T})$ there is no correlation between magnetic fabrics and 
magnetic mineralogy and there is a dominance of triaxial and prolate ellipsoids. Thermomagnetic curves indicate the dominance of paramagnetic behaviour in all the samples and except in one case there is a ferromagnetic contribution due to the generalised presence of magnetite.

Magnetic ellipsoids can be divided into four main types depending on the orientation of the main axes and associated with the lithologic types: 1) $K_{\max }$ vertical and $K_{\text {int }}$ and $K_{\min }$ horizontal for small intrusive bodies (no restoring); 2) $\mathrm{K}_{\max }$ horizontal or subhorizontal and $\mathrm{K}_{\text {int }}$ and $\mathrm{K}_{\min }$ included in a subvertical plane (before and after restitution) for volcanic breccias; 3 ) $\mathrm{K}_{\min }$ vertical (after restoring) and three directional maxima for lava flows and 4) non-defined fabric for the explosive materials (probably due to their complex depositional mechanisms). In general, a dominant E-W magnetic lineation is observed in many sites, resulting either from dominant flow direction, or to secondary processes. This is the case for some of the magnetic ellipsoids, that seems to be affected by deformation, $\mathrm{K}_{\min }$ is not normal to bedding and therefore, they do not become vertical after bedding restitution. 